\title{
DIFFERENT EFFECTS OF SOIL DROUGHT ON SOLUBLE CARBOHYDRATES OF DEVELOPING LUPINUS PILOSUS AND LUPINUS LUTEUS EMBRYOS
}

\author{
AgNiesZKa I. PIOTROWICZ-CIEŚLAK ${ }^{1}$, DARIUSZ J. MiCHALCZYK ${ }^{1}$, \\ BARBARA ADOMAS ${ }^{2}$, RYSZARD J. GÓRECKI $^{1}$ \\ ${ }^{1}$ Department of Plant Physiology and Biotechnology, University of Warmia and Mazury \\ Oczapowskiego 1A, 10-718 Olsztyn, Poland \\ e-mail: acieslak@uwm.edu.pl \\ ${ }^{2}$ Department of Air Protection and Environmental Toxicology, \\ University of Warmia and Mazury \\ Prawocheńskiego 17, 10-722 Olsztyn, Poland
}

(Received: June 19, 2006. Accepted: September 27, 2006)

\begin{abstract}
The aim of this study was to compare the accumulation of soluble carbohydrates in embryos of two lupin species: cultivated Lupinus luteus (cv. Juno) and wild L. pilosus, developing on plants grown under normal soil humidity and soil drought. All analysed seeds accumulated soluble carbohydrates, including: monosaccharides, sucrose, cyclitols, galactosyl cyclitols and raffinose family oligosaccharides.

Soil drought caused a nearly two-fold increase of soluble carbohydrate contents in both species. L. pilosus embryos however, responded to water deficiency by increasing the accumulation of cyclitols and galactosyl cyclitols, whereas L. luteus embryos enhanced accumulation of cyclitols and raffinose family oligosaccharides.
\end{abstract}

KEY WORDS: drought, Lupinus pilosus, Lupinus luteus L., seed, cyclitols, galactosyl cyclitols, raffinose family oligosaccharides.

\section{INTRODUCTION}

Water shortage in plants can be caused by salinity, high or low temperature, soil and atmospheric drought (Hanson and Hitz 1982). The most evident consequences of moderate water deficiency in plant tissues include growth limitation and changes in gene expression patterns, leading to the synthesis and activation of new metabolites and proteins (Farrant et al. 1996; Shinozaki and Yamaguchi-Shinozaki 1997; Cellier et al. 1998; Rizhsky et al. 2002). Moreover, the biosynthesis of non-structural carbohydrates may be modified, and these compounds are involved in the most basic physiological processes i.e. photosynthesis, transport and respiration (Madore 1990). Fruits and seeds seem to be little affected, probably because they are characterized by high growth activity and therefore they are very efficient sinks, capturing most of the transported assimilates stream (Kühn et al. 1997; Haritatos et al. 2000). However, certain changes in seed developing during drought conditions are visible and seed yield is the most evident of these (Frederick et al. 2001; Moinuddin and Khanna-Chopra 2004). Among soluble carbohydrates sucrose plays potentially the most important role in plant adjustment to drought stress (Keller and Ludlow 1993). In addition to being the trans- port form of carbon, sucrose sustains the liquid crystal/gel balance of membrane phospholipids and prevents structural changes in proteins. Unlike sucrose, the role of monosaccharides in drought resistance is ambiguous. They are respiratory substrates fuelling metabolic energy conversions. On the other hand, accumulation of monosaccharides may be harmful for the cells as these compounds can take part in protein glycosylation, the so called Maillard's reaction (Koster and Leopold 1988).

Accumulation of cyclic carbohydrates (cyclitols) during drought allows osmotic adjustment of plants (Wanek and Richter 1997). Cyclitols accumulation in the vacuoles reduces water potential of the cells and facilitates water uptake from the environment. Furthermore, cyclitols protect plants from photo-inhibition and free radicals (Orthen et al. 1994). Similarly, raffinose is accumulated in vegetative tissues during drought (Taji et al. 2002). Although functions of raffinose family oligosaccharides in development of drought stress resistance have not been sufficiently elucidated, it can be suspected that they are quite significant. They enhance seed tolerance to desiccation (Obendorf 1997) and induce seed acclimatisation to low temperature (Bachmann et al. 1994). 
In this study, reactions of seeds of two lupin species to drought stress were investigated. Genus Lupinus consists of species occurring both in the Old and New World. In the Old World there are 12 known perennial species constituting two separate groups: (1) Scabrispermae-rough seeded, including Lupinus pilosus and (2) Malacospermae-smooth seeded, including Lupinus luteus (Gladstones 1998).

The aim of the study was to determine the effect of drought on dynamics of accumulation and content of soluble carbohydrates (cyclitols, galactosyl cyclitols and raffinose family oligosaccharides) in the embryos of Lupinus pilosus and Lupinus luteus. In this way we wanted to see if the differences in seed coat structure, mentioned above (roughness/smoothness), are accompanied by different physiological characteristics of embryos.

\section{MATERIALS AND METHODS}

Yellow lupin (Lupinus luteus cv. Juno) and Lupinus pilosus plants were grown in 10-L pots in a greenhouse with a 12 -h photoperiod at $23^{\circ} \mathrm{C}$ day $/ 18^{\circ} \mathrm{C}$ night and $140 \mu \mathrm{mol}$ photons $\mathrm{m}^{-2} \mathrm{~s}^{-1}$ irradiance. Mixture of peat, garden soil and sand $(1: 1: 1, \mathrm{v} / \mathrm{v} / \mathrm{v})$ was used as substrate for plant growth. Until the day of flowering the plants were regularly watered to keep the relative soil humidity (RSH) at the level of $80 \%$. On the day of flowering the plants were labelled and divided into two groups: one was regularly watered as in previous days and in the second - the drought treatment $30 \% \mathrm{RSH}$ was obtained by limited watering. RSH was determined with an electronic soil humidity meter (IRE moisture meter UP-PRL-279462, Poland). Embryos were collected in five-day intervals, starting from 15 days after flowering (DAF) until full physiological seeds maturity. Germination ability and dry mass of the seeds were estimated according to ISTA (1996).

Cyclitols, galactosyl cyclitols and soluble sugars contents were analysed by GC chromatography according to the method of Piotrowicz-Cieślak (2005). Embryos (30-60 $\mathrm{mg}$ fresh mass) were homogenised in ethanol: water, 1:1 $(\mathrm{v} / \mathrm{v})$ containing $300 \mu \mathrm{g}$ phenyl- $\alpha$-D-glucose as internal standard. The homogenate and the rinse were combined in

TABLE 1A. Changes in visual characteristics of Lupinus pilosus seed maturing under different water availability; D - drought, C - control; all seeds shown in the same scale.

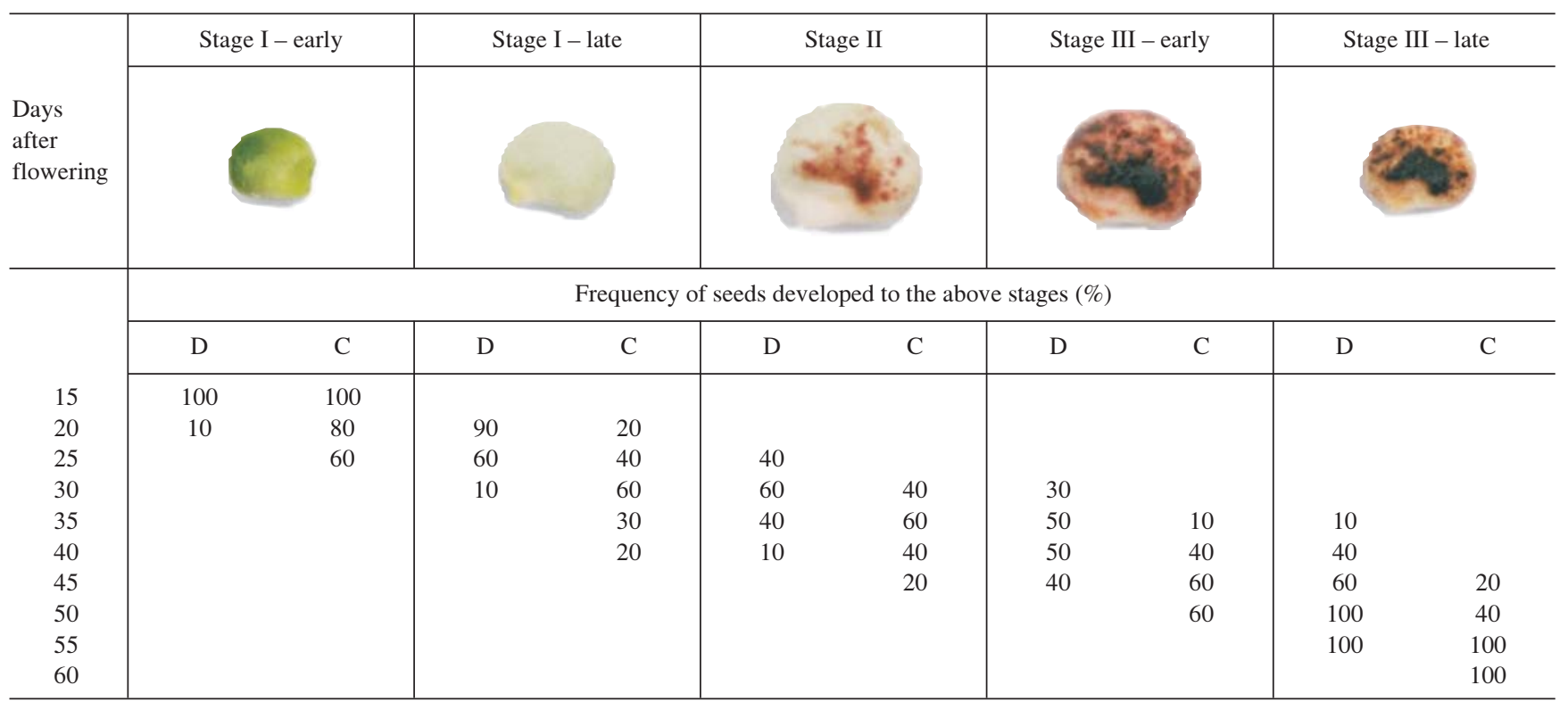

TABLE 1B. Changes in visual characteristics of Lupinus luteus seed maturing under different water availability; D - drought, C - control; all seeds shown in the same scale.

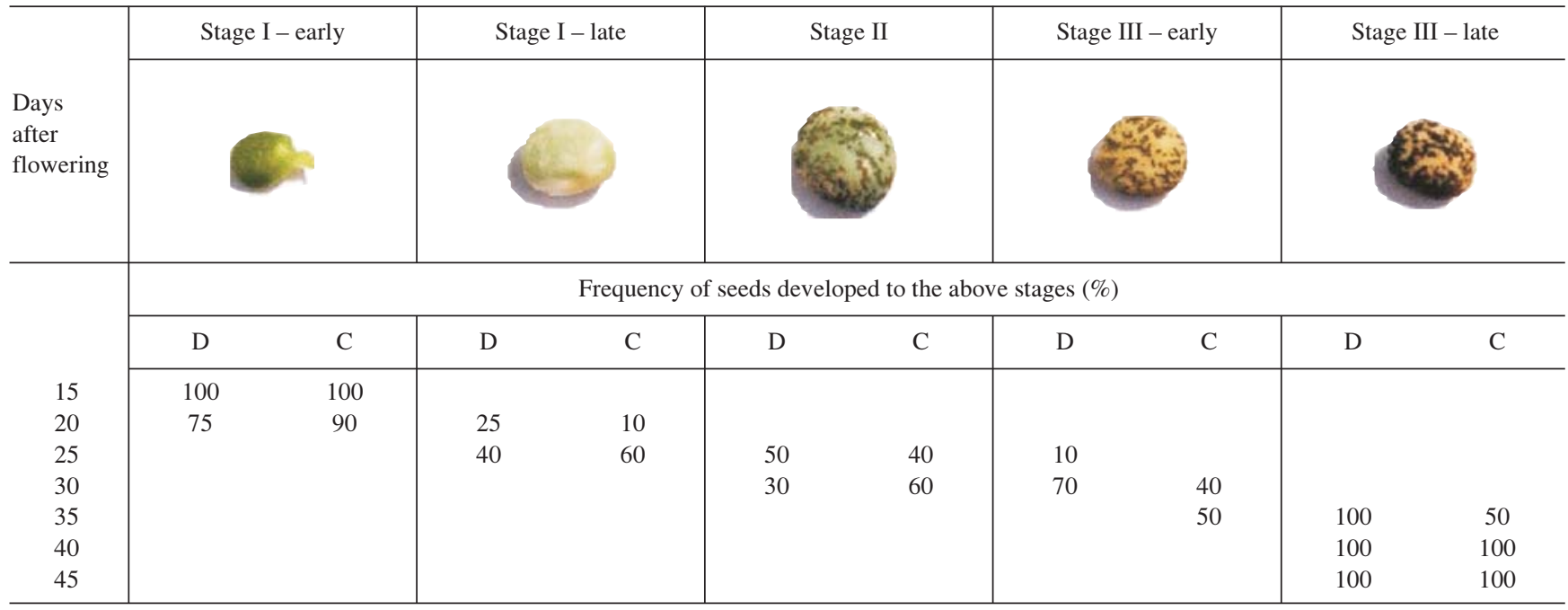


a $1.5-\mathrm{ml}$ microfuge tube, heated at $75^{\circ} \mathrm{C}$ for $30 \mathrm{~min}$ to inactivate endogenous enzymes and centrifuged at $15000 \mathrm{~g}$ for $20 \mathrm{~min}$. The supernatant was passed through a $10000 \mathrm{MW}$ cut-off filter (Lida, Kenosha, WI USA). Aliquots of $0.3 \mathrm{ml}$ filtrate were transferred to silylation vials and evaporated to dryness under a stream of nitrogen. Residues were kept overnight over phosphorus pentoxide in a desiccator. Dry residues were derived with $300 \mu$ of silylation mixture (trimethylsilylimidazole: pyridine, $1: 1, \mathrm{v} / \mathrm{v}$ ) in silylation vials (Supelco) at $70^{\circ} \mathrm{C}$ for $30 \mathrm{~min}$ and then cooled at room temperature. One $\mu 1$ carbohydrate extract was injected into a split-mode injector of a Shimadzu GC-14A gas chromatograph equipped with flame ionisation detector and Shimadzu C-R6A integrator. Soluble carbohydrate were analysed on a DB-1 capillary column (15 m length, $0.25 \mathrm{~mm}$ ID, $0.25 \mu \mathrm{m}$ film thickness, J\&W Scientific). Soluble carbohydrates were identified with internal standards as available and calculated from the ratios of peak area for each analysed carbohydrate to the peak area of respective internal standard.

Quantities of soluble carbohydrates were expressed as mean \pm SD for 3-5 replications of each treatment. Dry and fresh embryo mass were also examined.

\section{RESULTS}

\section{General characteristics of maturing seeds}

Seeds analysed differed in terms of the seed coat type, size and fresh mass, depending both on lupin species and maturation conditions. Mature L. pilosus seeds were characterized by rough coat, large seed size (above $10 \mathrm{~mm}$ ), dark pigmentation (Table 1A) and high fresh mass (523 mg, Fig. 1). Mature L. luteus seeds featured smooth coat, size up to $5 \mathrm{~mm}$ (Table 1B) and average fresh mass of 136 mg (Fig. 1). Drought clearly affected the accumulation of fresh mass in maturing seeds of both species. At the earliest stage of embryo maturation drought stress accelerated this process (Fig. 1). Later, this trend was reversed and at full physiological maturity the fresh mass of L. luteus embryos developing under optimum water conditions was higher by $35-36 \%$ compared to embryos of this species affected by drought. In L. pilosus the rate of maturation was also affected by drought stress. Under control conditions, seeds of this species reached full physiological maturity 60 days after flowering (DAF), whereas seeds subjected to drought stress matured at $55 \mathrm{DAF}$. In contrast, in L. luteus seeds the drought stress did not change the rate of maturation - full maturity was observed at 45 DAF in both control and drought stressed seeds.

Considering the fresh/dry mass accumulation, it was possible to distinguish three stages of seed maturity in both species (Fig. 1). At the first stage (15-25 DAF in Lupinus luteus and 15-30 DAF in Lupinus pilosus), parallel to a rapid accumulation of fresh mass, a slow increase of dry mass was observed. The second stage was characterised by a sudden decrease of fresh mass, indicative of transition to a state of natural desiccation and dynamic accumulation of dry mass (Fig. 1). This stage of maturation occurred at 30-35 DAF and 35-50 DAF in Lupinus luteus and in L. pilosus, respectively. At the third stage of maturation (40-45 in $L$. luteus and 50 to 60 in L. pilosus) seed dry mass continued to increase, although at lower rate (Fig. 1).
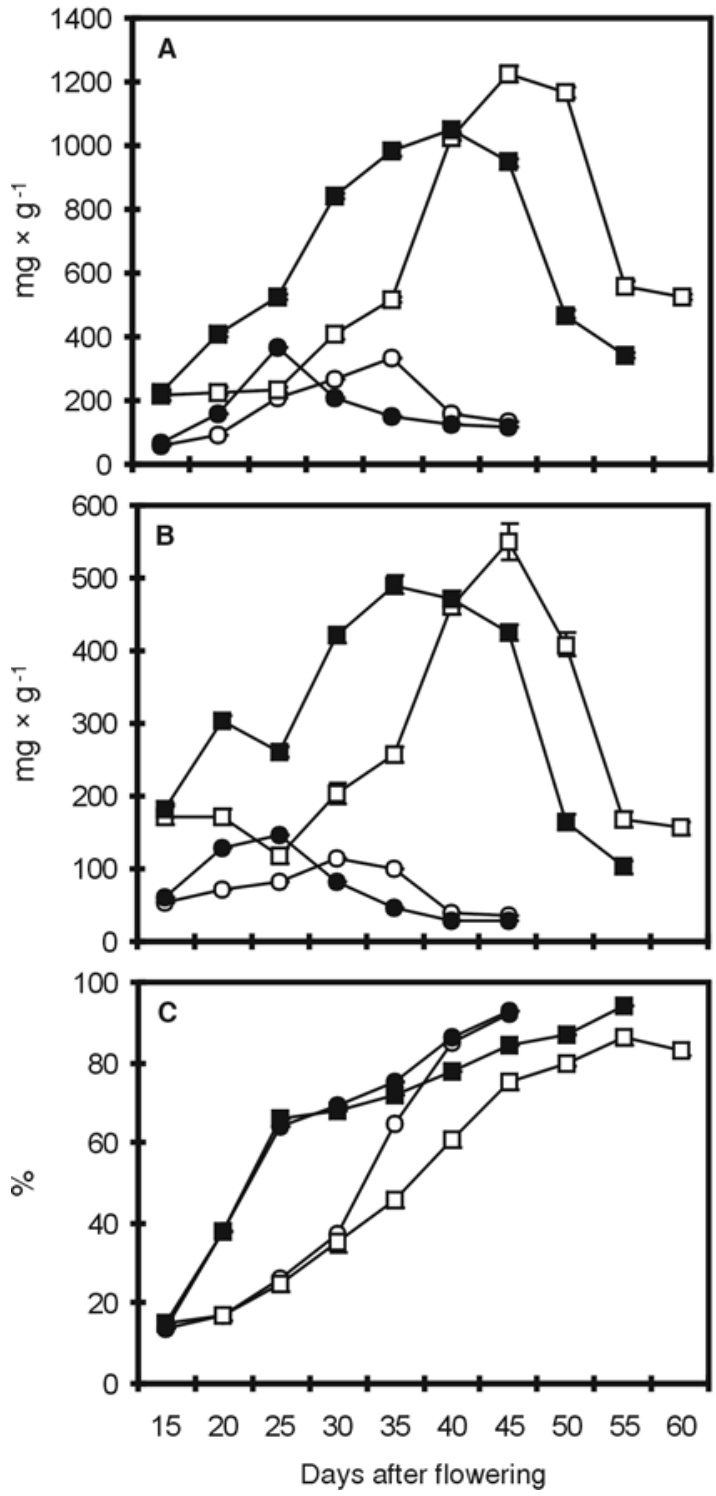

Fig. 1. Seed fresh mass (A), testa fresh mass (B) and seed dry mass (C) during growth and maturation. Data points represent the means \pm SD for fifteen replicate samples.

Lupinus luteus (O) - Control; (•) - Drought stressed

Lupinus pilosus $(\square)$ - Control; (ם) - Drought stressed

Under drought stress, seeds of L. luteus attained their maximum fresh mass $(365 \mathrm{mg} / \mathrm{seed})$ at $25 \mathrm{DAF}$, whereas seeds maturing under control conditions reached their maximum fresh mass $(330 \mathrm{mg} / \mathrm{seed})$ at $35 \mathrm{DAF}$. In L. pilosus the maximum fresh mass of seeds maturing under drought stress was $1222 \mathrm{mg} / \mathrm{seed}$ and in those maturing under control conditions $1048 \mathrm{mg} / \mathrm{seed}$, and both maximum values were recorded at $40 \mathrm{DAF}$. In the course of maturation seeds lost green colour, and this transition occurred in $L$. luteus between 25 and $35 \mathrm{DAF}$ and in L. pilosus between 35 and 45 DAF (Table 1A and 1B).

\section{Soluble carbohydrates of lupin embryos}

Maturing embryos of L. luteus and L. pilosus contained soluble carbohydrates including: monosaccharides (fructose, glucose, galactose), sucrose, raffinose family oligosaccharides (raffinose, stachyose, verbascose), cyclitols (myoinositol, D-chiro-insitol, D-pinitol) and galactosyl cyclitols (galactinol, digalacto-myo-inositol, galactopinitol A, ciceri- 

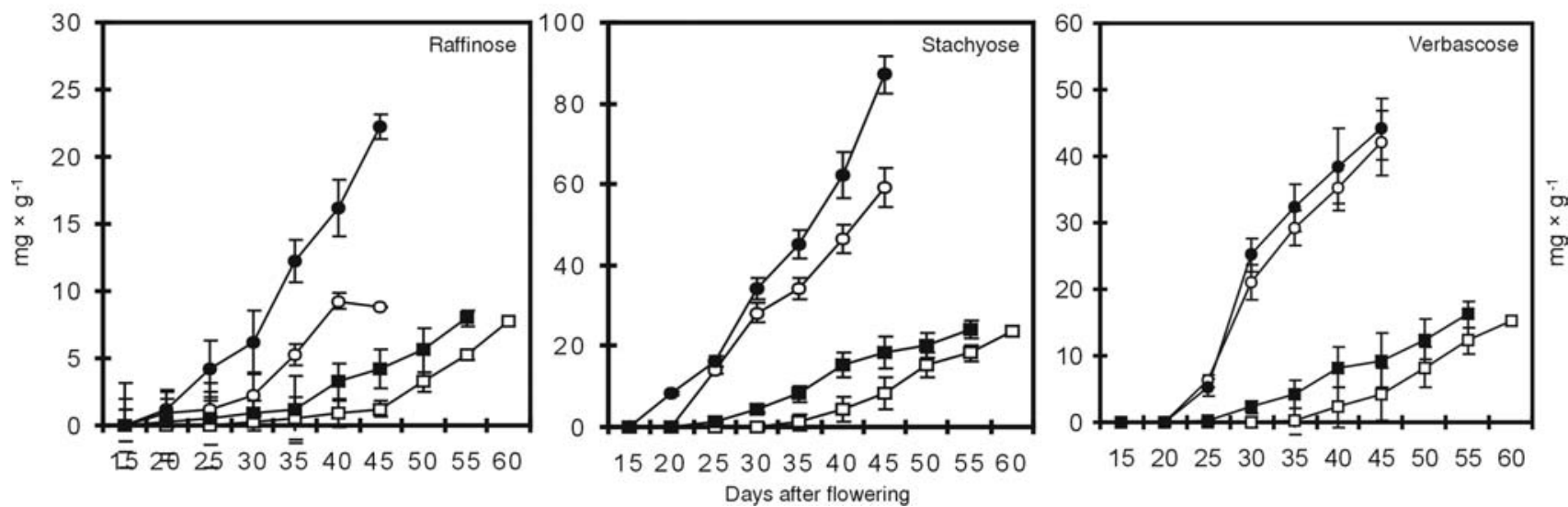

Fig. 2. Effects of drought on oligosaccharides (raffinose, stachyose and verbascose) contents of maturing embryos. Data points represent the means \pm SD of five measurements.

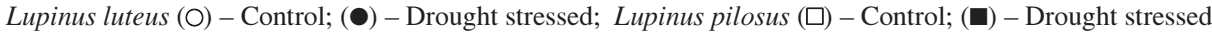
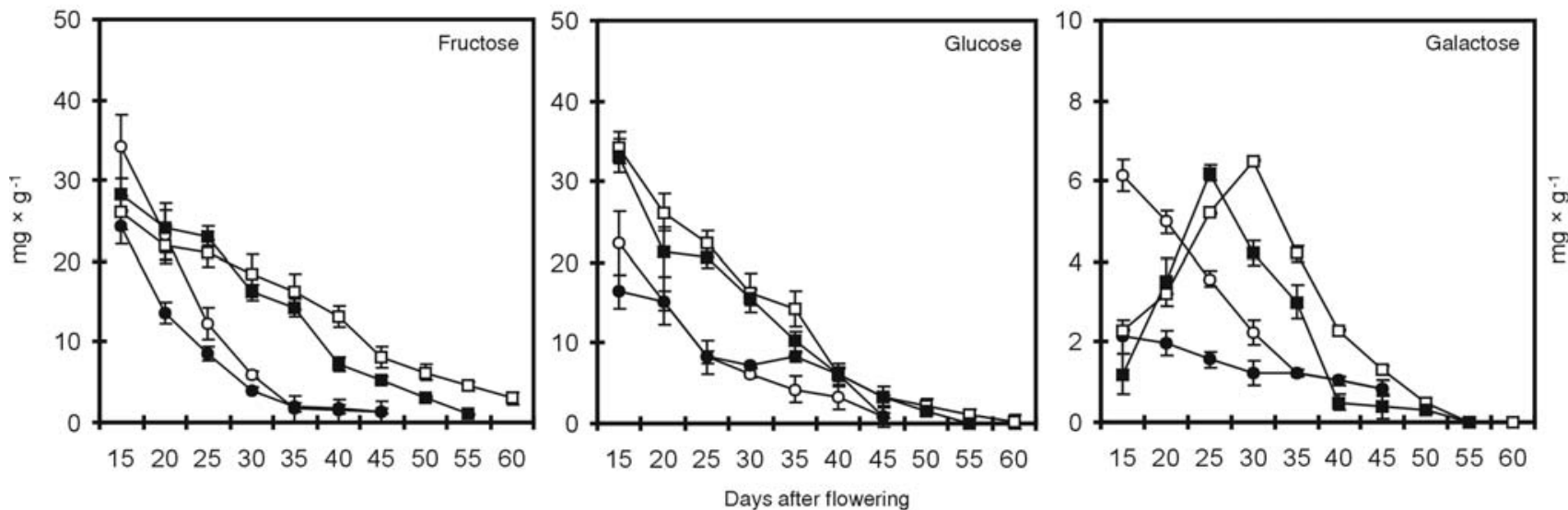

Fig. 3. Effects of drought on monosaccharides (fructose, glucose and galactose) content of maturing embryos. Data points represent the means \pm SD of five measurements

Lupinus luteus (O) - Control; (•) - Drought stressed; Lupinus pilosus $(\square)$ - Control; $(\mathbf{\square})$ - Drought stressed

tol, trigalactopinitol A, galactopinitol B, digalactopinitol $\mathrm{B}$ and trigalactopinitol B). Total content of soluble carbohydrates at full morphological maturity of L. luteus was $142 \mathrm{mg} / \mathrm{g}$ d.m. and $220 \mathrm{mg} / \mathrm{g}$ d.m for control and drought treatment, respectively. Similarly, L. pilosus seeds matured under control and drought conditions contained 130 $\mathrm{mg} / \mathrm{g} \mathrm{d} . \mathrm{m}$. and $184.5 \mathrm{mg} / \mathrm{g} \mathrm{d.m}$. total carbohydrates, respectively.

The main soluble carbohydrates of mature embryos in both L. luteus and L. pilosus were raffinose family oligosaccharides (RFO), among which stachyose dominated (Fig. 2). Stachyose accumulation in both species occurred during the second stage of seed maturation (natural desiccation). Raffinose and verbascose accumulation followed a similar temporal pattern as stachyose. Mature embryos of L. luteus grown under control conditions contained 8.86 $\mathrm{mg} / \mathrm{g}$ d.m. raffinose, $49.2 \mathrm{mg} / \mathrm{g}$ d.m. stachyose and 42.1 $\mathrm{mg} / \mathrm{g}$ d.m. verbascose. Embryos of L. pilosus contained at full maturity less raffinose, stachyose and verbascose 7.75, 43.1, 22.98 mg/g d.m., respectively. Drought resulted in an increase of RFO content of L. luteus embryos by about $50 \%$. In L. pilosus embryos maturing under drought stress RFO reached similar or slightly lower level compared to embryos matured under control condition (Fig. 2).

At the beginning of seed maturation (15 DAF) in embryos of both L. luteus and L. pilosus high contents of mono- saccarides were observed (Fig. 3). In the course of further maturation of L. luteus embryos, fructose, glucose and galactose contents decreased. In L. pilosus embryos the levels of fructose and glucose decreased, while the amount of galactose increased until $30 \mathrm{DAF}$ and levelled off thereafter. At full physiological maturity the embryos, both control and drought-affected, contained trace amounts of those sugars (Fig. 3).

Among galactosyl cyclitols, two groups of metabolites (myo-inositol series and D-pinitol series) were observed in mature embryos of examined species (Fig. 4). Galactinol accumulation increased at $30 \mathrm{DAF}$ (L. luteus) and $40 \mathrm{DAF}$ (L. pilosus). Embryos of Lupinus luteus seeds grown under soil drought conditions had significantly higher content of galactinol than control embryos.

Galactosyl cyclitols were present in cultivated lupin embryos in small quantities $8.58 \mathrm{mg} / \mathrm{g} \mathrm{d.m}$. and $8.08 \mathrm{mg} / \mathrm{g}$ d.m. under control and drought conditions, respectively (Fig. 4). In L. pilosus besides RFO, galactosyl cyclitols were the main carbohydrates in mature embryos. The contents of galactosyl cyclitols were $33.9 \mathrm{mg} / \mathrm{g} \mathrm{d} . \mathrm{m}$. and 67.3 $\mathrm{mg} / \mathrm{g} \mathrm{d} . \mathrm{m}$. in control and drought conditions, respectively.

During development and maturation of embryos in both species, an intense accumulation of sucrose occurred (Fig. 4). In control embryos maximum sucrose content was 46.91 mg/g d.m. (30 DAF) in L. luteus and $83.9 \mathrm{mg} / \mathrm{g}$ d.m. (40 


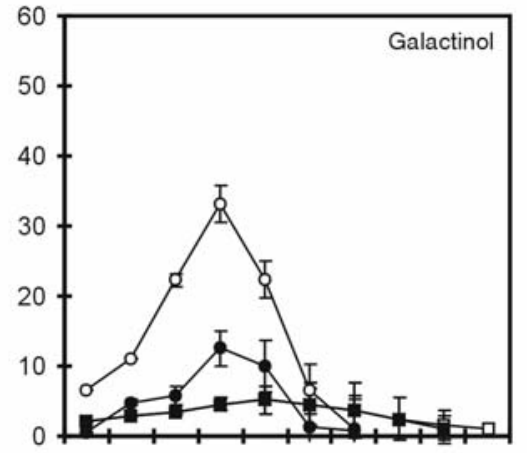

$\begin{array}{llllllllll}15 & 20 & 25 & 30 & 35 & 40 & 45 & 50 & 55 & 60\end{array}$

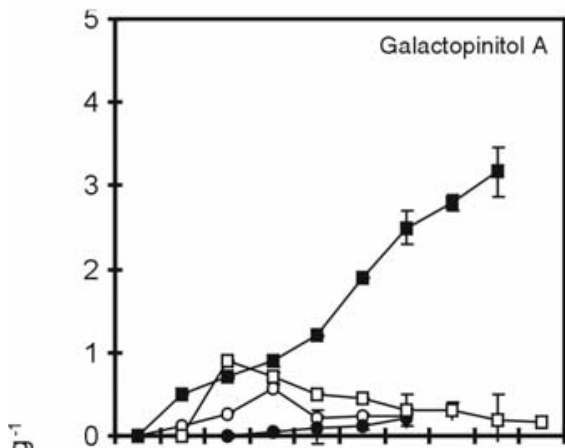

ס
$\times$
है

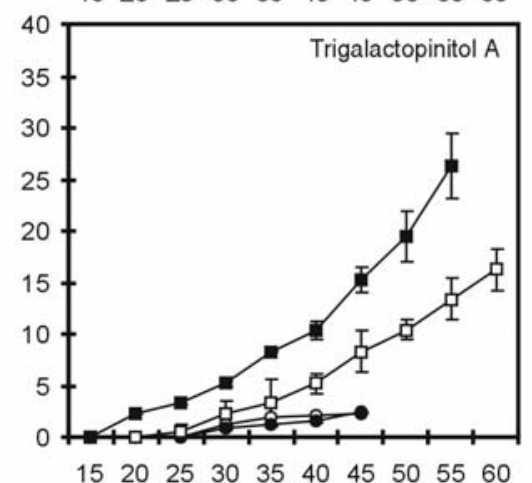

$\begin{array}{llllllllll}15 & 20 & 25 & 30 & 35 & 40 \quad 45 & 50 & 55 \quad 60\end{array}$

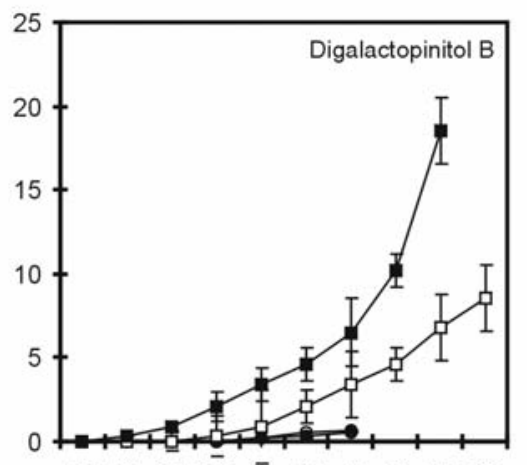

$\begin{array}{llllllllll}15 & 20 & 25 & \overline{30} & \overline{35} & 40 & 45 & 50 & 55 & 60\end{array}$

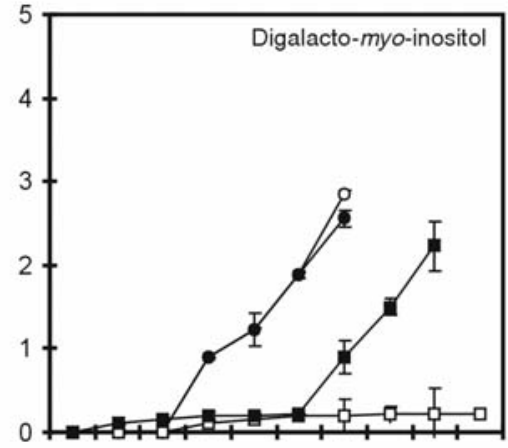

$\begin{array}{llllllllll}15 & 20 & 25 & 30 & 35 & 40 & 45 & 50 & 55 & 60\end{array}$

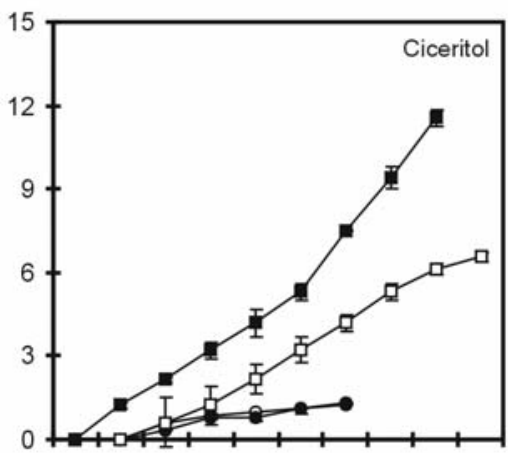

$\begin{array}{llllllllll}15 & 20 & 25 & 30 & 35 & 40 & 45 & 50 & 55 & 60\end{array}$

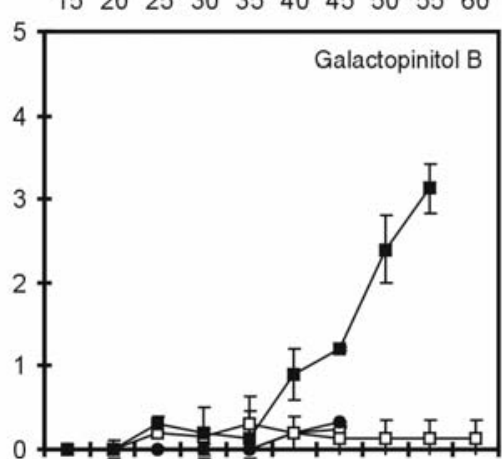

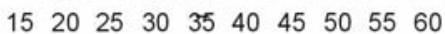

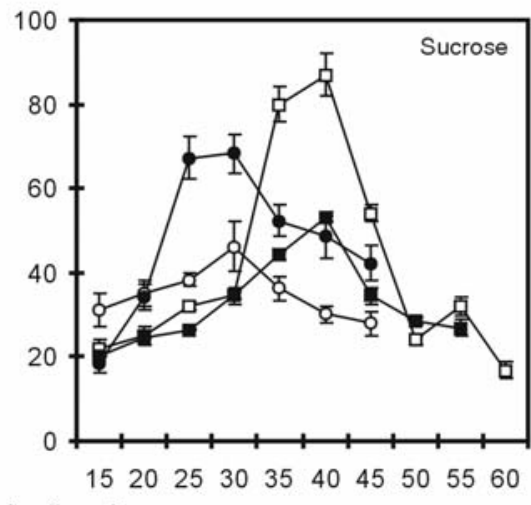

Fig. 4. Effects of drought on sucrose and galactosyl cyclitols (galactinol, digalacto-myoinositol, galactopinitol A, ciceritol, trigalactopinitol A, galactopinitol B and digalactopinitol B) contents of maturing embryos. Data points represent the means \pm SD of five measurements. Some data obtained for galactinol in control and stressed embryos of L. pilosus were very close and cannot be distinguished in this figure.

Lupinus luteus (○) - Control; (๑) - Drought stressed; Lupinus pilosus $(\square)-$ Control; ( $(\square)$ - Drought stressed

DAF) in L. pilosus. In drought-affected embryos of both species the maximum sucrose contents were higher (Fig. 4).

Seed maturation resulted also in quantitative changes of cyclitols in embryo tissues. At the beginning (15 DAF) D-pinitol and myo-inositol occurred in high and similar quantities (approx. $20 \mathrm{mg} / \mathrm{g}$ ) in control embryos of L. luteus and L. pilosus (Fig. 5). With seed maturation the levels of these metabolites declined gradually. Drought distinctly raised the initial levels of D-pinitol and myo-inositol in L. pilosus embryos, although it did not change their gradual decline parallel to maturation. In L. luteus embryos subjected to drought, D-pinitol concentration increased until 30 DAF, then levelled off. The amount of myo-inositol in these embryos changed in a similar pattern as in control embryos, although it was higher, particularly at the beginning of maturation. D-chiro-inositol occurred in all studied seeds in trace amounts only. 

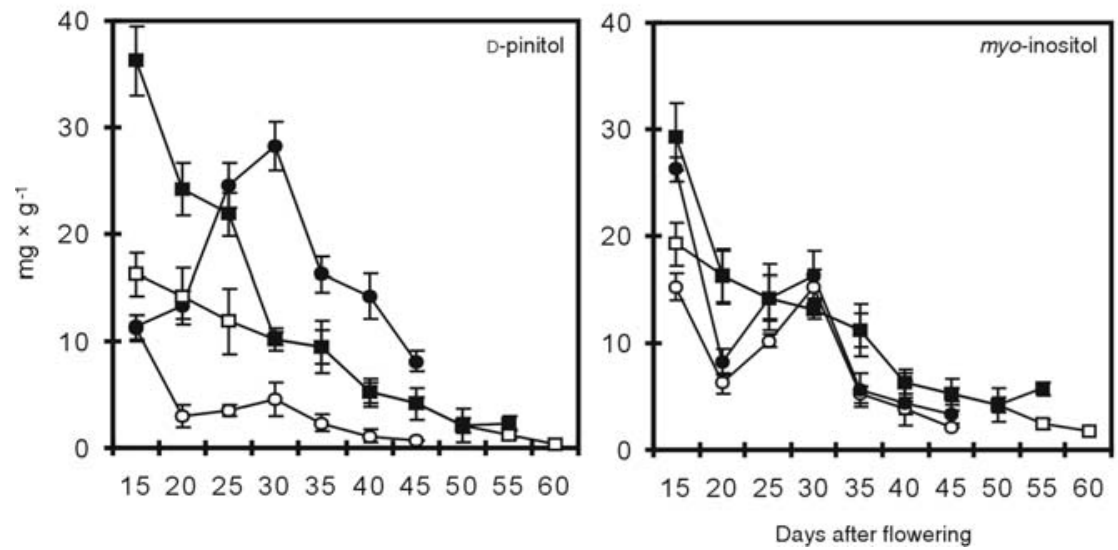

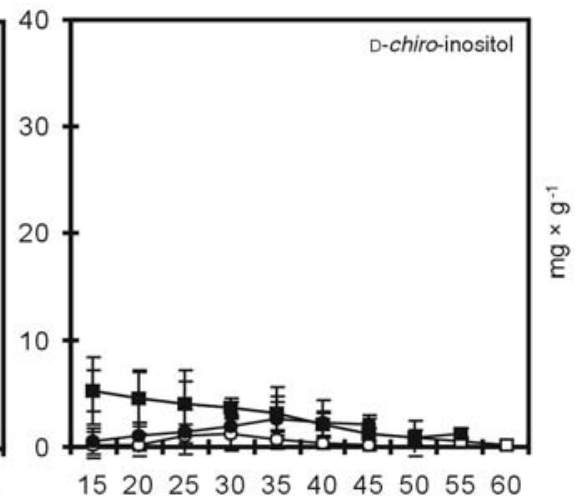

$15202530 \quad 3540 \quad 45505560$

Fig. 5. Effects of drought on cyclitols (D-pinitol, myo-inositol and D-chiro-inositol) content of maturing embryos. Data points represent the means \pm SD of five measurements. The data obtained for D-chiro-inositol in control and stressed embryos of L. pilosus were very close and cannot be distinguished in this figure.

Lupinus luteus (O) - Control; (•) - Drought stressed; Lupinus pilosus $(\square)$ - Control; $(\mathbf{\square})$ - Drought stressed

\section{DISCUSSION}

Seed chemical composition can be modified by various environmental factors. Drought enhances the accumulation of osmoprotective compounds in plant tissues, i.e. amino acids, betains, and carbohydrates including RFO, cyclitols and their galactosyl derivatives (Sun and Leopold 1993; Carpenter and Crowe 1989; Ramanjulu and Bartels 2002). It is believed that two factors are important for osmoprotective functions of carbohydrates: high number of hydroxyl groups and molecular mass (the higher, the better protection). The hydroxyl groups of carbohydrates bind polar groups of lipids and dissociate the intermolecular van der Vaals bonds and separate lipid chains. As a result, they keep the cell membrane fluid even at a very low level of hydration and low temperature (Crowe et al. 1996). Carbohydrates may lower the temperature of phase transition in lipids by binding them and increasing their molecular mass (Cacela and Hincha 2006), although it is not precisely clear how this binding should occur (Buitink et al. 2000). Verbascose, trigalactopinitol $\mathrm{A}$ and $\mathrm{B}$, and stachyose are among lupin osmoprotectants with the highest molecular mass (828 Da for verbascose), moreover verbascose contains particularly many hydroxyl groups (seventeen). Nevertheless, trehalose (containing only 8 hydroxyl groups and having the molecular mass 2.5 times lower than verbascose) was reported to be the most effective carbohydrate osmoprotectant (Crowe et al. 1984). However, lupin embryos do not accumulate trehalose, so its role must be played by sucrose or stachyose and other osmoprotectants. A hypothesis was put forward that plant cells, in order to well tolerate the desiccation, should contain sucrose at $10-15 \%$ dry mass or at the level of $5 \mathrm{~g}$ per gram lipids (Bianchi et al. 1993). However, the results of this paper do not corroborate this hypothesis. Lupin embryos contain sucrose at the level not exceeding 3\% dry mass (Fig. 4), and still they tolerate drought stress quite well. There are opponents of the above hypothesis among other authors as well (Leopold et al. 1994; Sun 1997; Pammenter and Berjak 1999). As shown in this paper, embryos of L. luteus accumulate high amounts of stachyose during maturation, and drought further raises the level of this metabolite (Fig. 2). Even a stronger stimulation by drought was observed in raffinose assays, though the absolute quantities of this metabolite were lower. In L. pilosus embryos, the contents of raffinose and stachyose also increased parallel to maturation and dehydration but they have always been much lower than in $L$. luteus. On the other hand, L. pilosus accumulated much higher amounts of D-pinitol and its derivatives compared to L. luteus. D-pinitol is considered an important osmoprotectant in soybean (Streeter et al. 2001). As shown in this paper, drought raises the amount of D-pinitol and its derivatives rather than members of the myo-inositol series in both L. luteus and L. pilosus embryos (Figs 4 and 5). However, our results show that there is a clear difference in galactosyl cyclitols composition between L. pilosus and L. luteus - galactopinitol A, ciceritol, trigalactopinitol A, galactopinitol $\mathrm{B}$, and digalactopinitol $\mathrm{B}$ occur at much higher levels in the first of these species than in the other one (Fig. 4).

The protective role of RFO and Gal-C in developing seeds is probably not limited to regulating the cell osmotic conditions. Oligosaccharide biosynthesis decreases the level of monosaccharides, and thus it limits the amount of reducing compounds and free radicals generated by these. Particularly, high levels of fructose, glucose and galactose can promote the Maillard reactions (Wettlaufer and Leopold 1991). The monoscaccharide levels in developing lupin seeds decreased and drought has accelerated this process (Fig. 3). Sucrose, RFO and galactosyl cyclitols readily bind galactose, thus eliminating its toxic effects. Two phases may be distinguished in the galactose metabolism in lupin seeds (Piotrowicz-Cieślak 2006). During the first stage (until the natural seed desiccation) galactose is incorporated into the thickening cell walls. Lupin cell walls contain galactans as well as arabinates, galactomannosides, rhamnogalacturonides and galactoxyloglucans (Al-Kaisey and Wilkie 1992). At the next stage (during and after desiccation, in our experiments 35-40 DAF; Figs 1 and 3), galactose is bound into RFO (this reaction dominates in $L$. luteus) and galactosyl cyclitols (particularly in L. pilosus).

To summarise, we obtained data suggesting that the two lupin species studied in this paper differ in their responses to drought: RFO accumulation predominates in Lupinus luteus and galactosyl cyclitols accumulation in L. pilosus. 


\section{LITERATURE CITED}

AL-KAISEY M.T., WILKIE K.C.B. 1992. The polysaccharides of agricultural lupin seed. Carbohydrate Res. 227: 147-161.

BACHMANN M., MATILE P., KELLER F. 1994. Metabolism of the raffinose family oligosaccharides in leaves of Ajuga reptans L. Cold acclimation, translocation and sink to source transition: discovery of the chain elongation enzyme. Plant Physiol. 105: 1335-1345.

BIANCHI G., GAMBA A., LIMIROLI R., POZZI N., ELSTER R., SALAMINI F., BARTELS D. 1993. The unusual sugar composition in leaves of the resurrection plant Myrothamnus flabellifolia. Physiol. Plant. 87: 223-226.

BUITINK J., LEPRINCE O., HOEKSTRA F.A. 2000. Dehydration-induced redistribution of amphiphilic molecules between cytoplasm and lipids is associated with desiccation tolerance in seeds. Plant Physiol. 124: 1413-1426.

CACELA C., HINCHA D.K. 2006. Low amounts of sucrose are sufficient to depress the phase transition temperature of dry phosphatidylcholine, but not for lyoprotection of liposomes. Biophys. J. 90: 2831-2842.

CARPENTER J.F., CROWE J.H. 1989. An infrared spectroscopic study of the interactions of carbohydrates with dried proteins. Biochemistry 28: 3916-3922.

CELLIER F., CONÉJÉRO G., BREITLER J.C., CASSE F. 1998. Molecular and physiological responses to water deficit in drought-tolerant and drought-sensitive lines of sunflower. Accumulation of dehydrin transcripts correlates with tolerance. Plant Physiol. 116: 319-328.

CROWE J.H., CROWE L.M., CHAPMAN D. 1984. Preservation of membranes in anhydrobiotic organisms: the role of trehalose. Science 223: 701-703.

CROWE J.H., HOEKSTRA F.A., NGUYEN K.H.N., CROWE L.M. 1996. Is vitrification involved in depression of the phase transition temperature in dry phospholipids? Biochim. Biophys. Acta 1280: 187-196.

FARRANT J.M., PAMMENTER N.W., BERJAK P., FARNSWORTH E.J., VERTUCCI C.W. 1996. Presence of dehydrin-like proteins and levels of abscisic acid in recalcitrant (desiccation - sensitive) seeds may be related to habitat. Seed Sci. Res. 6: 175-182.

FREDERICK J.R., CAMP C.R., BAUER P.J. 2001. Droughtstress effects on branch and mainstem seed yield and yield components of determinate soybean. Crop Sci. 41: 759-763.

GLADSTONES J.S. 1998. Distribution, origin, taxonomy, history and importance. W: Lupins as crop plants: Biology, production and utilization. (eds) J.S. Gladstones, C. Atkins, J. Hamblin. CAB International 1-40.

HANSON A.D., HITZ W.D. 1982. Metabolic responses of plant water deficit. Annu. Rev. Plant Physiol. 33: 163-203.

HARITATOS E., MEDVILLE R., TURGEON R. 2000. Minor vein structure and sugar transport in Arabidopsis thaliana. Planta 211: 105-111.

ISTA 1996. International rules for seed testing. Seed Sci.Tech. 24, Supplement 21.

KELLER F., LUDLOW M.M. 1993. Carbohydrate metabolism in drought-stressed leaves of pigeonpea (Cajanus cajan L.). J. Exp. Bot. 44: 1351-1359.
KOSTER K.L., LEOPOLD A.C. 1988. Sugars and dessication tolerance in seeds. Plant Physiol. 88: 829-832.

KÜHN C., FRANCESCHI V.R., SCHULZ A., LEMOINE V., FROMMER W.B. 1997. Macromolecular trafficking indicated by localization and turnover of sucrose transporters in enucleate sieve elements. Science 28 (275): 1298-1300.

LEOPOLD A.C., SUN W.Q., BERNAL-LUGO I. 1994. The glassy state in seeds: analysis and function. Seed Sci. Res. 4: 267-274.

MADORE M.A. 1990. Carbohydrate metabolism in photosynthetic and nonphotosynthetic tissues of variegated leaves of $\mathrm{Co}$ leus blumei Benth. Plant Physiol. 93: 617-622.

MOINUDDIN, KHANNA-CHOPRA R. 2004. Osmotic adjustment in chickpea in relation to seed yield and yield parameters. Crop Sci. 44: 449-455.

OBENDORF R.L. 1997. Oligosaccharides and galactosyl cyclitols in seed desiccation tolerance (Review Update). Seed Sci. Res. 7, 63-74.

ORTHEN B., POPP M., SMIRNOFF N. 1994. Hydroxyl radical scavenging properties of cyclitols. Proc. R. Soc. Edinb. Sect. B (Biol.) 102: 269-272.

PAMMENTER N.W., BERJAK P. 1999. A review of recalcitrant seed physiology in relation to desiccation-tolerance mechanisms. Seed Sci. Res. 9: 13-37.

PIOTROWICZ-CIEŚLAK A.I. 2005. Changes in soluble carbohydrates in yellow lupin seed under prolonged storage. Seed Sci. Tech. 33: 141-145.

PIOTROWICZ-CIEŚLAK A.I. 2006. Effects of temperature on the soluble carbohydrates accumulation of maturing yellow lupin seeds. Acta Physiol. Plant. 28 (4): 523-530.

RAMANJULU S., BARTELS D. 2002. Drought- and desiccation-induced modulation of gene expression in plants. Plant. Cell Environ. 25: 141-151.

RIZHSKY L., LIANG H., MITTLER R. 2002. The combined effect of drought stress and heat shock on gene expression in tobacco. Plant Physiol. 130: 1143-1151.

SHINOZAKI K., YAMAGUCHI-SHINOZAKI K. 1997. Gene expression and signal transduction in water-stress response. Plant Physiol. 115: 327-334.

STREETER J.G., LOHNES D.G., FIORITTO R.J. 2001. Patterns of pinitol accumulation in soybean plants and relationships to drought tolerance. Plant Cell Environ. 24: 429-438.

SUN W.Q. 1997. Glassy state and seed storage stability: the WLF kinetics of seed viability loss at T- $\mathrm{T}_{\mathrm{g}}$ and the plasticization effect of water on storage stability. Ann. Bot. 79: 291-297.

SUN W.Q., LEOPOLD A.C. 1993. Acquisition of desiccation tolerance in soybean. Physiol. Plant. 87: 403-409.

TAJI T., OHSUMI C., IUCHI S., SEKI M., KASUGA M., KOBAYASHI M., YAMAGUCHI-SHINOZAKI K., SHINOZAKI K. 2002. Important roles of drought- and cold-inducible genes for galactinol synthase in stress tolerance in Arabidopsis thaliana. Plant J. 29: 417-426.

WANEK W., RICHTER A. 1997. Biosynthesis and accumulation of D-ononitol in Vigna umbellata in response to drought stress. Physiol. Plant. 101: 416-424.

WETTLAUFER S.H., LEOPOLD A.C. 1991. Relevance of Amadori and Maillard products to seed deterioration. Plant Physiol. 97: $165-169$. 